\title{
ORBITAL NOISE IN THE EARTH SYSTEM IS A COMMON CAUSE OF CLIMATE AND GREENHOUSE-GAS FLUCTUATION
}

\author{
H.S. LIU, R. KOLENKIEWICZ, and C. WADE Jr. \\ NASA Goddard Space Flight Center \\ Greenbelt, MD 20771, USA \\ hanshou@core2.gsfc.nasa.gov
}

\begin{abstract}
The mismatch between fossil isotopic data and climate models known as the cool-tropic paradox The mismatch between fossil isotimate models of implies that either the data are flawed or we understand validity of the climate models on the scientific greenhouse warming. Here we question the validity of the climate models on the scientic background of orbital noise in the Earth system. Our study shows that the insolation pulsation induced by orbital noise is the common cause of climate change and atmospheric concentrations of carbon dioxide and methane. In addition, we find that the intensity of the insolation pulses is dependent on the latitude of the Earth. Thus, orbital noise is the key to understanding the troubling paradox in climate models.

Keywords: Orbital signals; frequency noise; climate fluctuation; celestial mechanics; earth system science.
\end{abstract}

\section{Introduction}

One of the great scientific challenges in Earth Science is to predict and understand climate change. Wrestling to meet this challenge is the discipline of Earth System Science (ESS). Polar ice and ocean-sediment cores have provided a picture of the last million years of Earth's climate history and marked the emergence of ESS as the discipline that deals with the Earth as a complex, interacting system. ESS takes atmosphere, ocean, land and biosphere as the main components of the Earth and seeks to understand major patterns and processes in their dynamics. To do this, we need to study not only the processes that go on within each component but also interactions between these components. Because we still do not understand all these geophysical processes and interactions, we can not, yet, build a simple but realistic model that reproduces cycles of 
the Earth's temperature and concentrations of the atmospheric greenhouse gases as revealed by the ice core records [1]. But this is the central goal of ESS.

ESS has a fundamental problem. How can we link models of geophysical processes to the greenhouse-gas concentration? The time scales involved in this question range from hundreds to millions of years and involve processes that are highly nonlinear [2]. Therefore, we are in an uncharted territory, performing an uncontrolled experiment with Earth dynamics that is terrifying in its scale and complexity.

Much of the current debate on the Earth's climate fluctuations is driven by the observation of atmospheric concentrations of greenhouse gases. ESS climate models with high levels of atmospheric carbon dioxide predict that global greenhouse warming would cause heating in the tropics, but fossil isotopic data have indicated cool tropical temperature during greenhouse episodes [3]. This mismatch between observation data and ESS climate models known as the cool-tropic paradox implies that either the data are flawed or we understand very little about the ESS climate models. On the scientific background of orbital noise in the Earth system $[1,2]$, here we question the validity of the ESS climate models. We present results from calculations of insolation pulsation that is induced by orbital noise of the Earth's changing obliquity. We show that global greenhouse warming phenomena during the past half million years were the effect and consequence of rapid temperature increases caused by insolation pulsation. In addition, we find that the intensity of the insolation pulsation is dependent on the latitude of the Earth. At high latitude, it provides extreme climate warming conditions for greenhousegas concentration. However, it decreases markedly in low-latitude regions, predicting cool tropical temperature during supposed greenhouse episodes.

\section{Insolation Signal}

Incoming solar radiation, generally called "insolation," is a key factor in climate studies. Deviation of insolation depends on orbital parameters, which characterize the orbit of the Earth around the Sun, and the Earth's axis of rotation. Equations of insolation deviations at any point on the Earth are governed by [4]

$$
F_{s}=F_{s}^{0} H \cos \psi_{s}\left(r_{0} / r_{s}\right)^{2}
$$

where $F_{S}^{o}=1368 \mathrm{Wm}^{-2}$ is the average amount of sunlight impinging on the Earth, $r_{\theta}$ and $r_{S}$ are the average and instantaneous distance from the center of the Earth to the center of the Sun, respectively, $\psi_{S}$ is the solar zenith angle. $H=1$ when $\cos \psi_{S} \geq 0$ and $H=0$ when $\cos \psi_{S}<0$. When $\cos \psi_{S}<0$ the Sun is below the horizon and the solar flux is zero. Eq. (1) has been developed in terms of 9 orbital parameters [4]. Averaging the diurnal and annual cycles, the zonal insolation signal to zero order in the orbital eccentricity $e$ becomes

$$
S(t)=F_{S}^{\phi}(t)=F_{S}^{0}\left(r_{0} / a\right)^{2}\left\{\frac{1}{4}+\frac{5}{16} P_{2}(\sin \phi)\left[\frac{3}{4} \sin ^{2} \varepsilon(t)-\frac{1}{2}\right]\right\}
$$

where $a$ is the semimajor axis of the orbit, $\phi$ is the latitude, $P_{2}(\sin \phi)$ is the ordinary Legendre polynomial of order 2 , and terms in $e^{2}$ and $e^{4}$ are dropped due to their small 
values compared to 1 . It is noted here that there is no precession $e(\sin \varpi)$ terms in Eq. (2) ( $\varpi$ is the argument of perihelion), such terms depend on season, and the average is zero. But the obliquity $\varepsilon(t)$ does appear. The changing obliquity can be expressed by

$$
\varepsilon(t)=\varepsilon_{0}+\sum_{i} A_{i} \cos \left(\gamma_{i} t+\zeta_{i}\right)
$$

where amplitude $A_{\mathrm{i}}$, frequency $\gamma_{\mathrm{i}}$ and phase $\zeta_{\mathrm{i}}$ for $\mathrm{i}=1,2,3 \ldots \ldots$ are constants and $\varepsilon_{0}=23.320556$ degree at $\mathrm{t}=0$ refers to $1950 \mathrm{AD}[5]$.

\section{Frequency Noise of Insolation}

The insolation signal $S(t)$ has been embedded in the frequency noise of the Earth's obliquity variations $[2,6]$. Based on a convolution theory of the non-stationary time series of orbital motion, the frequency noise of the insolation signal can be expressed by [7-9]

$$
N(t)=\frac{\mathrm{d}}{\mathrm{dt}}\left\{\arctan \left[\frac{\left\langle\Delta F_{s}^{\phi}(t)\right\rangle}{\Delta F_{s}^{\phi}(t)}\right]\right\}
$$

where $\Delta F_{S}^{\phi}(t)=F_{S}^{\phi}(t)-222.125 W^{-2}$ and

$$
\left\langle\Delta F_{S}^{\phi}(t)\right\rangle=\frac{1}{\pi} \int_{-\infty}^{\infty} \frac{\Delta F_{S}^{\phi}(t)}{t-\tau} \cdot \mathrm{d} \tau
$$

\section{Insolation Pulsation}

Insolation signal $S(t)$ in Eq. (2) and the frequency noise of the insolation $N(t)$ in Eq. (4) are shown in Fig. 1. The threshold model includes: (a) A threshold with two horizontal dashed lines, (b) A sub threshold signal of insolation at $65^{\circ} \mathrm{N}$ and (c) A frequency noise of the insolation $N(t)$. The addition of the frequency noise of the insolation enables the insolation signal $S(t)$ to cross the threshold. When the insolation signal $S(t)$ plus its corresponding frequency noise $N(t)$ increases across the threshold, an insolation pulse can be written to the time series. The quantized output is an insolation train. Insolation pulsation can be measured by calculating the integral of insolation deviations $\Delta F_{s}^{\phi}(t)$ over time for having only half obliquity cycle [9]. It last about $10 \mathrm{kyr}$ (one quarter of the obliquity period), and its total insolation surplus on the top of the atmosphere during the interglacial interval is about $10 \%$ more than that of the regular deglacial period of the obliquity variation. The insolation pulses during the past 420,000 years are also illustrated in Fig. 1.

The intensity of insolation pulsation (IIP) in terms of insolation surplus in Fig. 1 is dependent on latitude because the insolation signal $S(t)$ in Eq. (2) and insolation noise $N(t)$ in Eq. (4) are functions of the Legendre polynomial of $\sin \phi$ where $\phi$ is the latitude of the Earth. At high latitudes, the high IIP induces extreme climate warming conditions for greenhouse-gas concentration. But it decreases in low-latitude regions, predicting cool tropical temperature during supposed greenhouse episodes. 


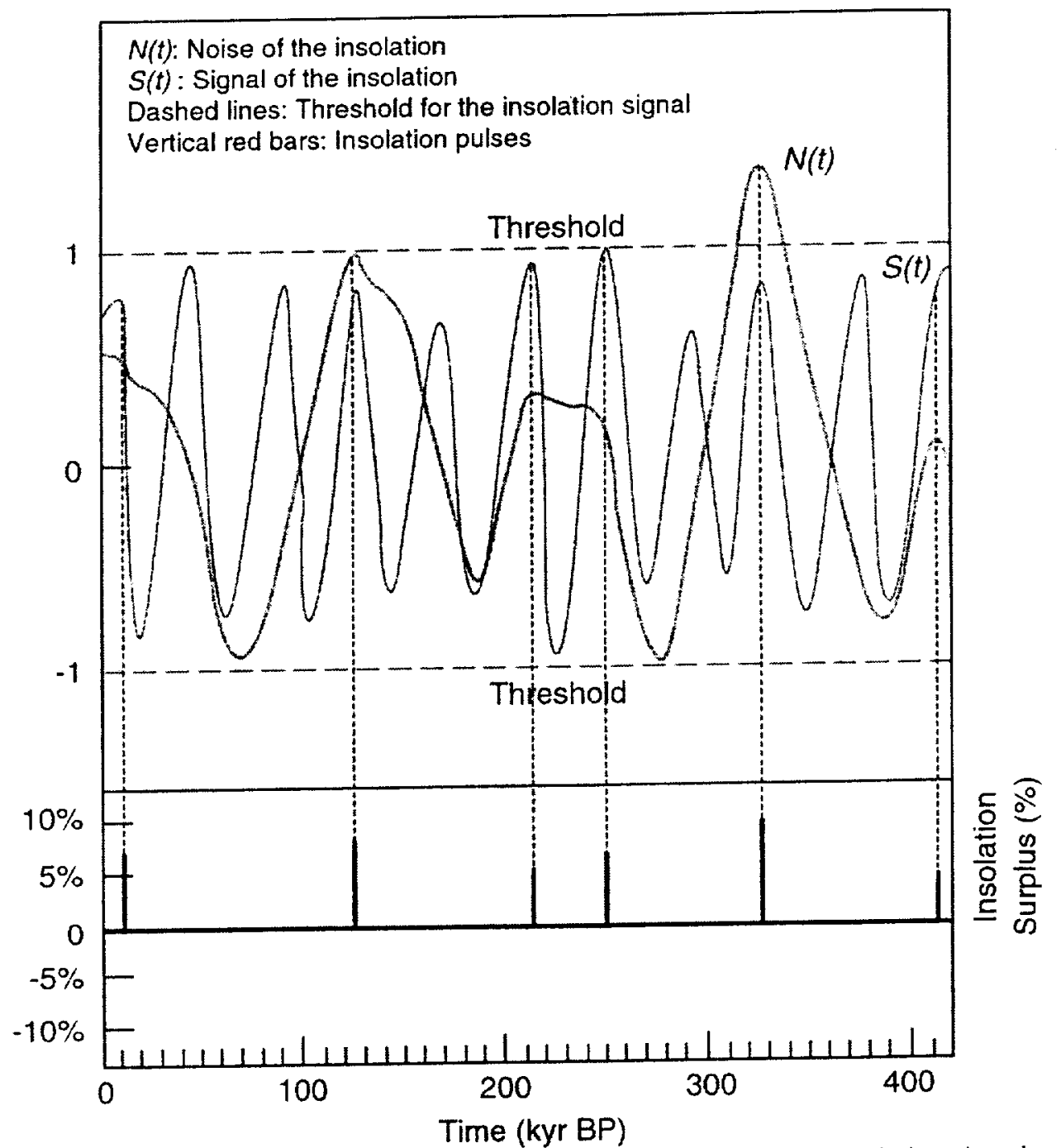

Fig 1. Noise-signal coupling effect on Rubincam's orbital insolation [4] induces pulsation in the incoming solar Fig I. Noise-signal coupling effect on Rubincam's orbital insolation [4] induces pulsation in the incold (two horizontal dashed lines) defines the maximum and minimum values of the insolation signal. Time is in kilo-years (kyr) before present (BP).

\section{Atmospheric Greenhouse-Gas Concentration}

The Earth's climate during the past one million years is punctuated by a series of large glacial-interglacial climate changes which are documented by complementary climate records, largely derived from deep sea sediments and ice cores. It has been shown that the variability of the glacial-interglacial climate change occurs with periodicity corresponding to that of the frequency noise of the Earth's changing obliquity [10,11]. 
Climate records give access to palaeoclimate series such as the Earth's temperature and atmospheric greenhouse-gas concentrations [3]. There is a close and strong correlation between global temperature and atmospheric $\mathrm{CO}_{2}$ and $\mathrm{CH}_{4}$. However, this correlation does not mean that greenhouse-gas concentration is the cause of glacialinterglacial climate change. In fact, atmospheric greenhouse-gas concentration may be the effect and consequence of the rapid temperature increase due to the orbitally induced insolation.

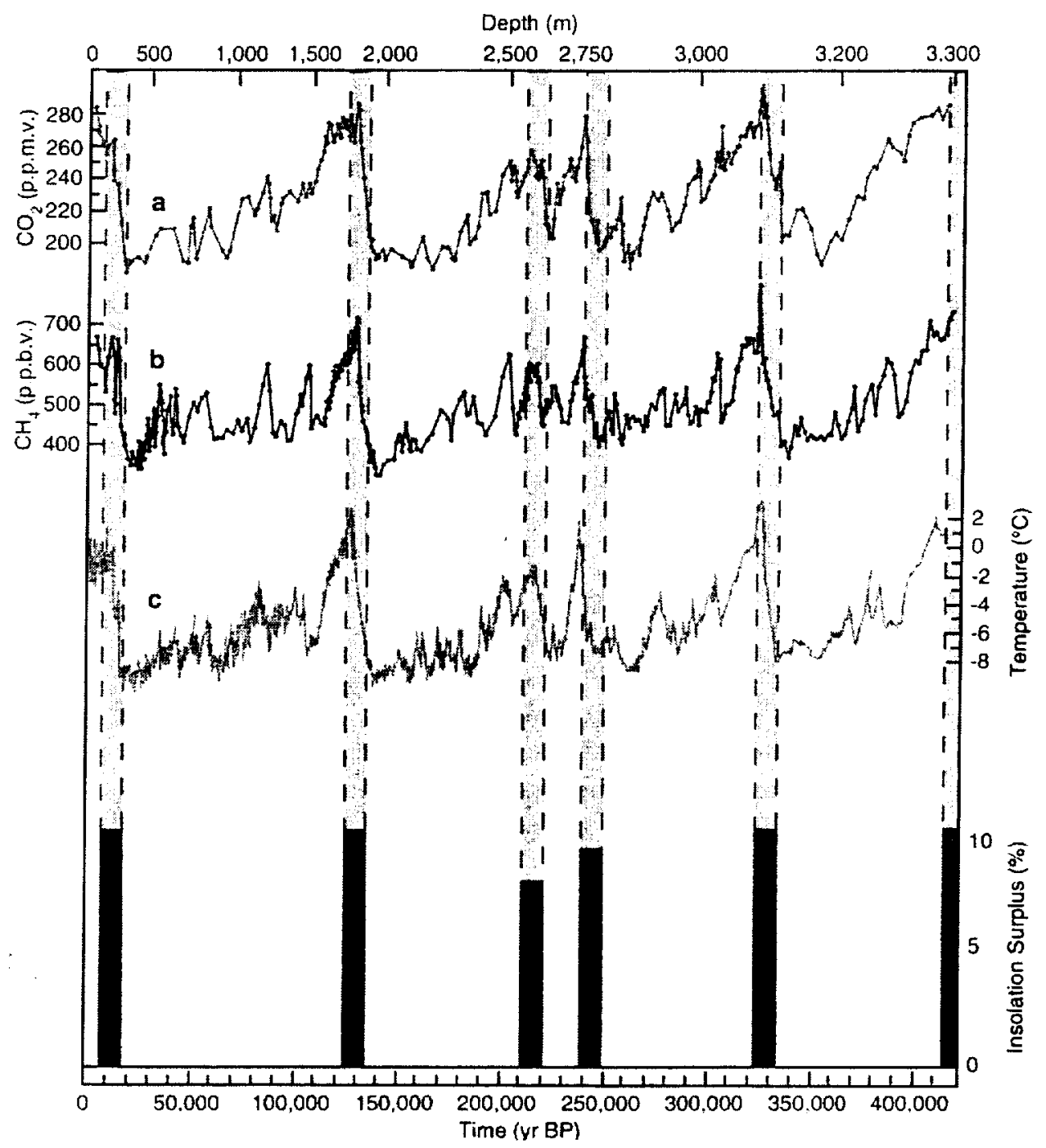

Fig 2. Orbital insolation pulses cause atmospheric concentrations of carbon dioxide and methane and glacialinterglacial temperature changes [3]. 
Insolation pulses induced by frequency noise of the Earth's obliquity are shown in Fig. 2, in comparison with the time series of temperature and the $\mathrm{CO}_{2}$ and $\mathrm{CH}_{4}$ concentrations as obtained by Petit et al. [3]. Each insolation pulse lasting about $10 \mathrm{kyr}$ will cause atmospheric concentration of $\mathrm{CO}_{2}$ and $\mathrm{CH}_{4}$ and rapid temperature increase for glacial-interglacial climate change as shown in (a), (b) and (c) in Fig. 2. During glacial inception, Petit et al. [3] have found that the $\mathrm{CO}_{2}$ decrease lags behind the temperature decrease. This may imply that atmospheric composition fluctuation is the effect of temperature variation.

Climate records also give access to palaeoclimate series that include precipitation rate and moisture source conditions. Particularly, the interglacial periods are characterized by much warmer temperature, increased precipitation and large-scale atmospheric moisture concentrations. It seems reasonable to suggest that atmospheric moisture concentrations are also the direct effect of insolation pulsation on climate change.

\section{Discussion}

Global greenhouse warming is controversial because the ESS climate models cannot reproduce cycles of ice ages and concentrations of the atmospheric greenhouse gases. Furthermore, models of $\mathrm{CO}_{2}$ greenhouse warming have confronted data from fossil planktonic foraminifera with the so called "cool-tropics paradox." The ESS climate models with high levels of atmospheric carbon dioxide predict that global greenhouse warming would cause heating in the tropics. But, in stark defiance of the global climate models $[3,12,13]$, the planktonic data seemed to suggest that ancient climates have indicated cool tropical temperature during supposed greenhouse episodes [14-19]. This has led researchers to question the primary role of $\mathrm{CO}_{2}$ in determining global temperature [20], while others have argued that the data may be biased [21-24]. In order to clarify the controversy and resolve this troubling paradox in climate models, we have studied how the global climate system is changing in response to insolation forcing [1,2,6-11] It has been found that the intensity of insolation pulsation, which is a function of latitude, is capable of reconciling the indisputably moderate polar and mid-latitudes conditions of the interglacial intervals with the planktonic data evidence that the tropical ocean was then barely warmer than the ocean at mid-latitudes. So small a latitude gradient would require an extraordinarily efficient heat-transport mechanism that only the insolation pulses can simulate.

The Milankovitch link [25] between orbital parameters and climate is rather old and weak. For the climate system subject to weak insolation signals, noise induced cooperative phenomena can often be set up, leading to stochastic resonance between the weak deterministic external insolation signal and the stochastic internal noise [26-31]. This resonance theory of climate is based upon internal mechanisms with the bio-cryoocean-atmosphere-lithosphere system believed to have response time on the order of the observed mean periodicity [32]. However, internal mechanisms or feed backs have difficulties in explaining the apparently episodic and irregular timing appearance of the glacial-interglacial temperature changes [33] and the cool-tropic paradox. 


\section{Conclusion}

We conclude that concentration of greenhouse gases in the atmosphere is the effect and consequences of insolation pulsation due to frequency noise of the Earth's changing obliquity. The insolation pulse provides extra solar heating above the high latitudes of the Earth and increases the temperature rapidly to terminate the ice age glaciation. The fact that the timing of the insolation pulses coincides with the occurrence of the atmospheric $\mathrm{CO}_{2}$ and $\mathrm{CH}_{4}$ concentrations supports the idea that insolation pulsation is the cause of the glacial-interglacial climate changes. These findings, together with our clarification of the cool-tropics paradox in climate models of global greenhouse warming, are of relevance with respect to the continuing debate on the future of Earth's climate.

\section{References}

[1] H. S. Liu, Obliquity modulation of the incoming solar radiation, Recent Res. Devel. Atmos. Sci. 1 (2001) 15-37.

[2] H. S. Liu, Orbital noise in the Earth's system and climate fluctuations, ICNF'2001, Noise in Physical Systems and 1/f fuctuations, World Scientific, Singapore (2001) 801-804

[3] J. R. Petit, J. Jouzel, D. Raynaud, N. I. Barkov, J. -M. Barnola, I. Basile, M. Bender, J. Chappellaz, M. Davis, G. Delaygue, M. Delmotte, V. M. Kotlyakov, M. Legrand, V, Y, Lipenkov, C. Lorius, L. Pepin, C. Ritz, E, Saltzman, and M. Stievenard, Climate and atmospheric history of the past 420,000 years from the Vostok ice core, Antarctica. Nature 399 (1999) 429-436.

[4] D. P. Rubincam, Insolation in terms of Earth's orbital parameters. Theor. Appl. Climatol. 48 (1994) 195-202.

[5] J. Laskar, Secular evolution of the solar system over 10 million years, Astron. Astrophys. 198 (1988) 341-362.

[6] H. S. Liu and B. F. Chao, Wavelet spectral analysis of the Earth's orbital variation and paleoclimate cycles, J. Atmos. Sci 55 (1998) 227-236.

[7] H. S. Liu, Phase modulation of the Rubincam insolation variations on climate change, Theor. Appl. Climatol. 61 (1998) 217-229.

[8] H. S. Liu, Glacial-interglacial changes induced by pulse modulation of the incoming solar radiation, J. Geophy. Res. 103 D20 (1998) 26, 147-26, 164.

[9] H. S. Liu, Insolation changes caused by combination of amplitude and frequency modulation of the obliquity, J. Geophy. Res. 104 B 11 (1999) 25, 197-25, 206.

[10] H. S. Liu, Frequency variation of the Earth's obliquity and the $100 \mathrm{Kyr}$ ice-age cycles, Nature 358 (1992) 397-399.

[11] H. S. Liu, A new view on the driving mechanism of Milankovitch glaciation cycles, Earth and Planet. Sci. Lett. 131 (1995) 17-27.

[12] E. J. Barron, Eocene equator-to-pole surface ocean temperature: a significant climate problem? Paleoceanography 2 (1987) 729-739.

[13] L. C. Sloan and D. K. Rea, Atmospheric carbon dioxide and early Eoceneclimate: A general circulation model sensitivity study, Palaeogeogr. Palaeclimato. Palaeoecol. 119 (1995) 275-292.

[14] D. Rind, Latitudinal temperature gradients and climate change, J. Geophys. Res. 103 (1998) 5943-5971.

[15] T. Bralower, J. C. Zachos, E. Thomas, M. Parrow, C. K. Paull, D. C. Kelly, I. P. Silva, W. V. Sliter, and K. C. Lohmann, Late Palaeocene to Eocene paleoceanography of the equatorial Pacific Ocean: Stable isotopes recorded at Ocean Drilling Progam Site 865, Allison Guyot. Paleoceanography 10 (1995) 841-865.

[16] B. Wade, Western north Atilantic palaeogene and cretaceous palaeoceanography, Special Publ. 183, Geological Soc. London (2001) 273-291. 
[17] D. Hondt and M. A. Arther, Late Cretaceous oceans and the cool tropic paradox, Science 271 (1996) 1838-1841.

[18] D. Hondt and M. A. Arther, Interpecies variation in stable isotopic sinals of Maastrichtian planktonic foraminifera, Paleoceanography 10 (1995) 123-125.

[19] T. J. Crowley and R. A. Berner, $\mathrm{CO}_{2}$ and climate change, Science 292 (2001) 870-872.

[20] J. Veizer, Y. Godderis and L. M. Francois, Evidence for decoupling of atmospheric $\mathrm{CO}_{2}$ and global climate during the Phanerrozoic eon, Nature 408 (2000) 698-701.

[21] J. S. Killingley, Effect of diagenetic recrystallization on $180 / 160$ values of deep-sea sediments, Nature 301 (1983) 594-597.

[22] P. A. Willson and B. N. Opdyke, Equatorial sea surface temperatures for the Maastrichtian revealed through remarkable preservation of metastable carbonate. Geology 24 (1996) 555-558.

[23] D. P. Schrag, Effect of diagenesis on the isotopic record of late Paleogene tropical sea surface temperature, Chem. Geol. 161 (1999) 215-244.

[24] P. N. Pearson, P. W. Ditchfield, J. Singano, K. G. Harcourt-Brown, C. J. Nicholas, R. K. Olsson, N. J. Shackleton, and M. A. Hall, Warm tropical sea surface temperatures in the late Cretaceous and Eocene epochs, Nature 413 (2001) 481-487.

[25] M. Milankovitch, Mathematische Klimalehre und Astronomische Theorie der Klimaschwankungen I, Part A, Handbuch der Klimatologie, Borntrager, Berlin (1930) 176.

[26] R. Benzi, A. Sutera, and A. Vulpiani, The mechanism of stochastic resonance, J. Phys. A: Math. Gen. 14 (1981) L453-L457.

[27] R. Benzi, G. Paris, A. Sutera, and A. Vulpiani, Stochastic resonance in climate change, Tellus 34 (1982) 10-16.

[28] A. Sutera, Stochastic perturbation of a pure convection motion, J. Atmos. Sci. 37 (1980) 245-249.

[29] A. Sutera, On stochastic perturbation and long-term climate behavior. Quart. J. Roy. Meteor. Soc. 107 (1981) 137-151.

[30] G. Matteucci, Orbital forcing in a stochastic resonance model of the late-pleistocene climate variation, Climate Dyn. 3 (1989) 179-190.

[31] C. Nicolis, Stochastic aspects of climate transitions-response to a periodic forcing. Tellus 34 (1982) 1-9.

[32] J. Imbrie, A. Berger, E. A. Boyle, S. C. Clemena, A. Duffy, W. R. Howard, G. Kukla, J. Kutzbach, D. G. Martinson, A. McIntyre, A. C. Mix, B. Molfino, J. J. Morley, L. C. Paterson, N. G. Pisias, W. L. Prell, M. E. Raymo, N. J. Shackleton, and J. R. Toggweiler, On the structure and origin of major glaciation cycles 2. The 100,000 year cycle, Paleoceanography 8 (1993) 699-735.

[33] L. Beaufort, Climate importance of the modulation of the $100 \mathrm{kyr}$ cycle inferred from $16 \mathrm{~m} . \mathrm{y}$. long miocene records, Paleoceanography 9 (1994) 821-834. 